\title{
Bio Refinery of Oily Wastes
}

\author{
José Vega Baudrit ${ }^{1,2}$ \\ ${ }^{1}$ Poliuna, School of Chemistry, Universidad Nacional de Costa Rica, Costa Rica \\ ${ }^{2}$ National Nanotechnology Laboratory LANOTEC-Ce NAT, San José, Costa Rica
}

Juan José Rojas Alfaro ${ }^{1 *}$, Luis Marcial Fernández Araya ${ }^{1}$, Carlos Redondo Gómez² and

Submission: May 11, 2018; Published: May 25, 2018

"Corresponding author: Juan José Rojas Alfaro, Poliuna, Chemistry School of Chemistry, Universidad Nacional de Costa Rica completar direccion, Costa Rica, Email: jvegab@gmail.com

Abstract

Many attempts have been made in order to establish a concept for biorefinery. The simplest way to do so is in an analogous way to the current oil refinery, where multiple fuels and products are manufactured from fossil source, but in the biorefinery scenario, biomass is converted into a range of biochemicals, materials and energy products in an industrial process.

\section{Introduction}

\section{The Concept of Bio-Refinery}

Another approach includes "the sustainable processing of biomass into a spectrum of marketable products and energy", therefore, allows defining biorefineries as "integrated bio-based industries, using a variety of different technologies to produce chemicals, biofuels, food and feed ingredients, biomaterials (including fibers) and power from biomass raw materials" [1,2]. The concept of biorefinery has evolved to take into consideration several criteria as technology, material, products, industry, or any other combination of the above [3]. Besides chemicals and energy, biorefinery may also provide biproducts as food for humans and livestock. This could support populations against food shortages and bring an alternative carbon and nitrogen fermentation sources (cellulose-rich waste an animal waste, respectively) $[2,4]$. Due to the highly varying composition of carbohydrate, lipids, and proteins content among biomass, Biorefineries needs to include several processes to obtain the chemicals or fuels of interest. Because of this, it is necessary to follow initial pretreatment and separation steps (primary biorefinery) before focusing on the, conversion processes that yield the o obtain biochemical building blocks of interest, i.e., a set of functional molecules suitable for organic synthesis (secondary biorefinery) $[1,3]$. In order to target the biorefinery's goal, an industry must implement a mixture combination of technologies and unit operations to deal with biomass conversion and energy production. Among theose, it is possible to mention fermentation, gasification, pyrolysis, hydrothermal liquefaction, hydrogenation, hydrothermolysis, oxidation and hydrodeoxygenation [5].

\section{Motivation}

Biorefineries come as a reasonable solution to cope with increasing concerns regarding fossil fuel reserves, the strong dependency of contemporary societies to obtain chemicals and raw materials from the former, climate change as an indisputable reality, an increasing limitation in food and energy availability as the world population is expected to keep increasing at a swift rate, and last but not least, the waste management originated when dealing with these increasing demands. Biorefineries happen to provide a way to deal with all these concerns while providing innovative solutions [6]. Biomass has acquired an important position in order to replace fossil fuels because of it is a renewable character, it also can reduce carbon dioxide air concentrations in as an important fraction of the former is caused by waste plastic incineration [4]; in this fashion greenhouse effect could be reduced, and slow down global warming [7]. Besides that, the waste management issue could be addressed by recycling and treating agro- and food waste to include them as biorefinery starting materials. As a consequence of the many toxicology reports on chemical compounds released to the environment each year, there is an increasing need to substitute them, as to improve the market offer with safer options [7]. The list of products for substitution will quickly grow longer as the new legislation gets approved [8].

Thus, the development of technologies for establishing successful biorefineries has been actively pursued [9]. Biorefinery serves the dual role of reusing disposal while producting useful products [4], so by using new technologies 
able to bridge the gap between the economic growth and environmental sustainability while providing alternative of energy sources [2]. Also, renewable biomass resources can be converted into chemicals, and have the potential to replace fossil crude oil as a carbon resource [5]. For instance, vegetable and animal fats can be used as efficient sources for energy and bulk chemicals production. Vegetable oil and animal fats possess have a huge potential market for biodiesel production and can also serve as a large platform in the synthesis of glycerol, fatty acid methyl esters, soaps, paints, candles, bioplastics, lubricants, and many other value-added products [10].

\section{Types De-Biorefinery}

In relation to biomass resource, Biorefineries can be classified into two types: biomass producing- country type and waste-material utilization type [4]. However, biorefinery is more than a fixed technology since it comprises a collection of unitary processes, a number of biorefineries classifications has been proposed based on the routes from feedstocks to products; [2]. Biomass producing-type biorefineries have dedicated crops to obtain the biomass, meanwhile waste-material type use residual streams from food production, various other agricultural uses, garden waste, etc. [11]. Moreover, biorefineries could be dedicated to one main product or many products in order to take advantage of the heterogeneous biomass. In relation to business feasibility, many products form the so-called "product portfolios" and the profits from fast-growing products can be invested in the development of future promising goods [4]. Considering the type of biorefinery and biomass proposed to reuse, the following strategies could be develop according to [11].

a. Embrace their heterogeneous nature of the initial biomass and convert as much as possible of its the components into small molecules such as syngas, which can be used in the chemical industry.

b. Another approach consists on developing specific reactions to convert single components into valuable building blocks that can be recovered from the complex mixture at low cost and energy inputs.

c. First separate the biomass components into 'homogeneous' components like protein, fats, starch, cellulose, hemicellulose, lignin and minerals and then convert each of these into 'pure' building blocks that can be separated from the (usually aqueous) supernatants.

\section{Biorefinery of Oily Wastes}

Many biomass resources have been evaluated for biorefinery applications, including crops, agricultural waste, forest resources, urban and industrial waste and algae [5]. Among them, oily wastes represent a risk for water contamination due to its oxidation potential and biochemical degradation processes. Esthetic appearance and putrefaction odor generated as animal fats degradate represent additional is another complications to mishandling this kind of wastes. But far from representing difficult materials to work with, oily wastes are a prominent resource because their lipid content, variety of derivate molecules, and stored energy.

\section{Exploitable Oily Residues}

Oily residues can be mainly classified into three categories: vegetable oils, glycerol from diesel or biodiesel production, animal fats. Their study has been called oleochemistry and represents is an emulating sector that allows the development of various products [6]. Oils usually are obtained from seeds and microalgae but cooking oil is also an option to profit from in biorefineries. Oilseeds provide a unique opportunity for the production of biofuel by esterification process (sunflower, rape, soybean or palm are the most used to produce biodiesel) and high-value free fatty acids that can replace petrol sources of specialty chemicals. Oilseeds contains various triacylglycerols based on fatty acids and they have very interesting combination of physical and- chemical characteristics (inert, high viscosity index, low volatility) attractive for several industrial applications [6]. Other instances of oily sources can be found in used cooking oil and bio-oil. Used cooking oil is commonly obtained from food industries' and restaurants, its consist mainly on vegetable oils which can be used in biofuel production [10]. On the other hand, bio-oil is a dark brown, free-flowing or viscous liquid having a smoky distinctive odor, obtained from fast/flash pyrolysis and hydrothermal liquefaction (HTL) [12]. Glycerol is considered a by-product from biodiesel production, its high availability originates in the fact that it is the main by-product of biodiesel production by trans esterification of oil with methanol or ethanol; as 9 parts of biodiesel are generatesd 1 part of glycerol is produced as well : $9(\mathrm{w} / \mathrm{w})$. Glycerol chemistry has gained attention on the past years due to its flexibility and potential to produce interesting precursors useful in organic chemistry, this situation encouraged significant developments of glycerol conversion technologies [6].

Although glycerol can be burned as a fuel, it can also be processed into more valuable commodity chemicals. Its highly functionalized nature means that glycerol can readily be oxidized, reduced, halogenated, etherified, and esterified to obtain alternative commodity chemicals. Glycerol oxidation produces synthons for the chemical industry, polyglycerols and esters that can be used in coatings and adhesives, glyceryl carbonate is valorized as a plasticizer and propanediol and ethylene glycol (obtained through the hydrogenolysis of glycerol) useful in polymer synthesis and also as solvents. Recent studies are using glycerol as a carbon source for microorganisms [6]. Glycerol is an important intermediate metabolite of living organisms, therefore it is an ideal carbon source for microbial fermentation/ metabolism. Several microorganisms are able to ferment glycerol and synthesize a number of products with a wide range of functionalities, thu reducing the employment of refined sugars for media formulation [13]. Another family of oily residues of 
interest for the biorefinery industry comprise a Animal fats: edible and non-edible ones. Instinctive edible fats are beef tallow, pork fat goose or duck fat, edible gelatin. In order to consider the quality and safety of the animal fats, they are classified either as either food grade or used for technical purposes. Inedible fats are utilized in feed, as pet food, in the production of oleochemicals, as biodiesel, or in energy generation [10].

\section{Treatment Processes}

Waste management guarantees discharge under ecofriendly regulation standards, but there are plenty of plausible treatment technologies to use. Primary, solid waste treatment can be subdivided into biological and thermal treatment. Thermal processing is related to energy recovery, Following wastewater technologies are classified as either chemical, physical, and biological. The main benefit of employing the biological treatment lies in the recapture of stabilized organic stock and nutrients. On the other hand, physical pretreatment requires less energy but is less effective in recovering both energy or and compounds. Finally, biological treatment, as fermentation, demands higher energy but have yields much higher reductions, so chemical processes stand as intermediate selections [14].

Biomass pre-treatment steps involve mainly phase separation operations as, size reduction and particle, removing, centrifugation, drying, pressing, classification, but also pyrolysis and fermentation among others [11]. These treatments are responsible for $20-40 \%$ of the total costs of terminated products in biorefinery [3]. When higher solid concentrations are present, sedimentation can be adopted as first step combined with other technologies such as coagulation-flocculation, dissolved air flotation and centrifugation. Coagulation-flocculation consists on aggregating single stocks to larger flocs, thus overcoming the hurdle of repulsion with equicharged particles, these techniques are commonly used to ensure settlement rates of equal to or higher than $0.6 \mathrm{~cm} / \mathrm{s}$. However the toxicity of the chemicals used in flocculation is often problematic as long as biomass can be contaminated, limiting, its applicability. As an alternative, auto flocculation can be achieved without the addition of supplementary chemicals, to necessary adjust the $\mathrm{pH}$ conditions and only affords lower settlement rates compared to the traditional flocculation approach [15].

Centrifugation has been used to separate particles for over 100 years in the mineral industry, and has been widely adapted and used successfully in many commercial applications [15]. It is usually, applied when dry cake is required and so it produces clarified liquids; it is applied in oil removing from water, the removal of ink from paper fibers, and waste water treatment, just to mention a few examples. There is a large portfolio of valueadded products that can be obtained from biomass by using a Range of with the thermochemical biorefinery process. Among those, Several technologies such as pyrolysis, gasification, torrefaction, and hydrothermal liquefaction, are the principals techniques to efficiently modify the biomass [2]. Pyrolysis consists on the thermochemical decomposition of biomass at rank to $350-700{ }^{\circ} \mathrm{C}$ in the absence of oxygen. Pyrolysis of biomass yields solid, liquid, and gaseous products of interest for energy production [12]. The integration of thermal pyrolysis process is generating interest because of the plausibility to convert waste materials into readily useful products [16].

Hydrothermal liquefaction (also denominated as solvolysis, hydrothermal upgrading, hydrothermal processing, and direct liquefaction), involves the reaction of biomass in water at temperatures around $200-400{ }^{\circ} \mathrm{C}$ and high pressures in between 5-20 MPa, it may or not involve the use of a catalyst to increase bio-oil yield. In this process water is the most commonly used solvent, because it is abundant, renewable and relatively cheap, but organic solvents have been used sometimes as to increase both bio-oil yield and quality, like ethanol, acetone, 2-propanol, methanol, 1, 4-dioxane, toluene, and in some cases glycerol [12]. On the other hand, hydrothermal liquefaction is conducted in aqueous media which makes it suitable for aquatic plants, but the high pressures involved results in higher investment cost which is the main limiting factor for its commercialization at the moment [12]. Gasification converts organic waste based carbonaceous materials into $\mathrm{CO}$ and $\mathrm{H} 2$, burned with a controlled amount of oxygen at high temperatures [10].

Nevertheless, high moisture content feedstocks require more time and energy consuming unit operations and that is about $65 \%$ of the general biomass [17]. For this reason thermochemical routes are less attractive and costly compared to anaerobic and aerobic fermentation systems [5]. Fermentation converts the source of carbon and energy into: acids, gases, or alcohols. This process it's mediated by microorganisms like yeasts and bacteria, on a growth aqueous medium [3] and renders a chemical product out of, waste material [3]. As water is required in fermentation processes cost-effectiveness assessment deserves additional attention in order to evaluate its feasibility [1].

\section{Areas of Application of Biorefinery}

Biorefinery is an extensive and multidisciplinary field; this technology could offers the possibility to provide plenty of complementary routes in the preparation of bulk and fine chemicals while helping to reduce the current the environmental impact. Following the new rolls of the green chemistry, there are several possibilities to be produced from waste, biofuels, heat, fine chemicals, cosmetics, bioplastics and composites [6]. Biorefinery related technologies, have shown to be quite convenient to include as part of existing industries and have happened to actually displace some of them, as more environmental awareness and finite fossil resources will turn out to be scarcer with the passing of time [18]. On the other hand, the sustainability of biorefinery systems may underperform technologies based on nonrenewable sources, but the optimization of the processes concerns as the principal objective to generate significant benefits as a whole 
integrated industrial target. for the generation of more attractive high-value bioproducts in market [18].

\section{Utility of Biomass}

As more awareness arises on the severe environmental risk that organic wastes represent, biomass is becoming an appealing alternative not only for reducing our current dependency on oil-derived organics but also for accessing more feasible routes towards greener fine and bulk chemical products as well as reducing carbon prints of industries. Biorefinery approaches come up as handy as biomass is often provided by non-comestible feedstocks and organic wastes to be used as raw materials [19], nevertheless not the all feedstock and wastes products are sustainability approached in the biorefinery production [5]. The main types of biomass are defined as a function of its composition as well as its place of origin [12]. In this context, [20], established the following is four classes of feedstocks:

a. First Generation: entails edible biomass, starch rich, oily plants, to produce bioalcohols, vegetable oil, animal food, biodiesel, biosyngas, industrial biochemical, and biogas [2]. Food industries make tons of edible waste that can be come up for a vast number of products [6].

b. Second Generation: Uses biomass in the form of nonfood sources and crops, residual nonfood parts of crops, solid waste, wheat straw, etc. To produce bio alcohols, bio oil, biohydrogen, biomaterials, and biodiesel [2]. The energy found in agricultural residues is often useful for the production of bio products, providing a different scenario for the utilization of the same biomass [5].

c. Third Generation: includes algae to produce vegetable oil, biodiesel and fine chemicals. A range of bioproducts can be processed from microalgae, such as fatty acids and carotenoids, pigments, pharmaceutical compound, biodiesel, glycerin, cosmetic and biomass for animal feed $[10,15]$.

d. Fourth Generation: uses vegetable burned oil to produce biogasoline and biodiesel [2]. Modified oil esters can be used as a base for in the preparation of environmentally friendly fuels whose. Recent investigations are paving the way for using burned oil as biomass, nowadays its use is just discarded $[10,15]$.

\section{Biofuels}

Since 2010 more than 11 billion tons of oil is consumed every year, oil reserves are vanishing at a rate of 4 billion tons a year and many studies have projected that the crude oil reserves will be exhausted between 2050 and 2075, thus. Increasing fuel costs [10]. In recent years, substantial research has been carried out on liquid fuel production from biomass. Bioethanol and biodiesel biofuels have been extensively investigated and industrialized around in developed countries, this has been possible thanks to the employment of both. edible biomass (even though it caused harsh debates food wastes and non-edible feedstocks in biofuel production, the latter are still undergoing investigated [12]. Most of these studies have focused on culture methods and cultivation systems engineering, genetic and metabolic engineering, efficient biomass harvest measures, biofuel conversion technologies, thermal technologies, fermentation technologies, cost-effectiveness evaluation, life cycle assessment, and policy implications [1]. In addition, developed countries are encouraging R\&D initiatives on the production of alternate fuels. Biodiesel consists on fatty acid methyl esters, produced by the transesterification technique of fatty acids, from vegetable oils, animal fats, or others sources, with a suitable alcohol, being methanol the most common choice. The typical fatty acids found in biodiesel production comprise between 4 and 22 carbon atoms in their alkyl chains [21]. Biodiesel has the characteristic to emit not only fewer but also nontoxic pollutants. In the other hand, ignition properties of biodiesel are quite similar to generic diesel, and hence biodiesel can be blended with other oils [10]. Biodiesel can be produced from any fatty acid containing material in a substantial proportion, whether this are free way or covalently bound to other molecules.

Thus, various vegetable oils, animal fats, waste greases, edible oil-processing and agriculture wastes can be used as feedstocks for biodiesel production. The selection of feedstock is built on such variables as: local availability, cost, government support, and performance of the final fuel. Biodiesel made from animal fats and used cooking burned oil produces less greenhouse gas emission as compared to the soy biodiesel which are nearly 2.5 times higher. When using the trans esterification technique, also a second product of interest is obtained, at least $10 \mathrm{~kg}$ of crude glycerol are generated per each $100 \mathrm{~kg}$ of biodiesel produced out of vegetable oils or animal fats [10].

About $95 \%$ of the global production of biodiesel from edible vegetable oil because of the current abundance of crop production around the globe. Biodiesel current demands involve round one third of the vegetable oil consumption worldwide [22]. Algae have been long considered as one of the alternative sources for biofuel production. Algae are a group of photosynthetic eukaryotic organisms, ranging from unicellular to multicellular forms [12]. Their favorable biochemical machinery converts them into appealing candidates in the production of marketable products, their lipids can comprise an astonishing fraction of the microalgae weight (lipids (10\%), carbohydrates (15\%), and proteins (35\%) $[1,12,15,22]$. Microalgae's have got a big number of potential advantages compared to higher plants and other vegetable species, because of their faster growth rates, high photosynthetic efficiency, high lipid content, noncompetition for farm lands, and toleration to wastewaters during cultivation [1]. Increasing prices of diesel and the many cons linked to its use keep stimulating research on biofuels refinery; in 2013 about 116.6 billion liters of biofuel were produced globally. That's why biodiesel is the second largest category of global biofuel, accounting $22.6 \%$ of the total biofuel production. Bioethanol 
occupies the first place with $75 \%$ of the total [22]. The European Union is expected to become the largest producer of biodiesel throughout the next decade, the continent produced $40 \%$ of the global biodiesel in 2013, and the United States contributed 20\% as a single nation, followed by Germany and Brazil with $16 \%$ and $5 \%$ respectively $[10,21]$.

\section{Fine Chemicals}

Biomass should also be used in other large scale applications, in particular as feedstock for the production of substances difficult to synthetize [7]. Undoubtedly, the development of new resources for the chemical industry will lead to new products such as biopolymers, alcohols, esters, sugars, proteins, carotenoids, surfactants and polyaromatic organic compounds, all of whose production costs can be lowered [11]. These chemicals can be produced via microbial fermentation, starting from organic waste, and can be further converted to other valuable or commodity products $[1,9]$. A variety of bioactive substances, such as $\beta$-carotenoids, polysaccharides, antioxidants, poly-unsaturated fatty acids, generally produced in a low volume in high scale, have also been extract from biomass, and current possess significant market demand [2]. Many processes including transesterification, incur in the formation of by-products named oil gels, also known as oleogels. This kind of materials have piqued researcher's interests as can be used as low molecular weight gelators for modifying formulations and tuning their rheological properties [7]. Also, the uses of glycerol can be an inexpensive and preferred carbon source for the production of complex chemicals as succinic acid, surfactants and 1, 3-propanediol [9]. Microalgae have also found a niche in the fine chemicals production, as some complex chemical structures of interest in pharmaceutical and cosmetic industries can be found in their cultures [6].

\section{Bioeconomy Related Aspects}

Biorefineries venture into a dynamic and growing part of bioeconomies as it offers the promise of renewable sources in addition to more favorable environmental characteristics compared to fossil fuels counterparts [18]. According to Transparency Market Research Inc., the oleochemical industry will expand from 13 Mtons to 15 Mtons by 2018 [10]. Currently, fatty acids productions rounds 6.5 Mtons while installed capacities can stand up to 8 Mtons a year; also their market value is expected to increase from $\$ 0.8$ billion to $\$ 1.3$ billion by 2018 [17] Biorefineries offer numerous business opportunities. There are important potential profits along virtually all kinds of biomasses, by 2010 approximate profits were: agricultural inputs, $\$ 15000$ million; biomass production, $\$ 89000$ million; biomass trading, $\$ 30000$ million; biorefining inputs, $\$ 10000$ million; biorefining chemicals and downstream chemistry, $\$ 6000$ million; biorefining fuels, $\$ 80000$ million; biomass power and heat, $\$ 65000$ million [9]. Considering the above, many influential global companies, such as Cyanotech, Seambiotic, MeraPharma and FujiChemical, are operating at big scale to produce important compounds in cosmetics, nutritious feed and pharmaceuticals fields because of their increased added value [1]. It is also expected that the global market of biofuels will increase from almost $\$ 80000$ million in 2011 to $\$ 185000$ million in 2021 [23].

However, biofuels have been generally impugned for most of the increase in prices of agriculture crops. In addition, there has been an extraordinary escalation in palm oil and soybean oil production. Indonesia and Malaysia are the largest producers and exporters of vegetable oils, accounting for $60 \%$ of global exports [10]. Oil from marine fishes is a new oil source, about $75 \%$ of fish oil is used in the production of fish feed, $11 \%$ is used for human consumption, and the rest is used for other applications $[15,18]$. Nonetheless, large centralized biorefineries may also find their plathce in the market, for example in the production of highly specialized bioproducts [18]. Finally, the aspiration to valorize wastes over and done with treatment moves up a new and exciting waste hierarchy that is likely to nurture the bioeconomy [19].

\section{Challenges and Remarks}

Besides the great developments achieved so far by biorefineries, there are many considerations and technical, legal, social, and economic challenges to be addressed in the future. The most efficient valorization of biomass is the real intention of biorefineries, but, in order to remain competitive in the chemical industry, several current processes should achieve higher efficiency and real industrial integration, their efficiency could be measured by use of energy, water, and process flow sheeting [14]. The development of a global biorefinery is an enormous plan, where several participants are required, including many companies and governmental initiatives [4]. To cover that, integration in the total chain has therefore a remarkable effect on the sustainable performance of biorefinery systems. Usually, as higher the integration levels of the biorefineries better the economic and environmental performance [18]. As biorefinery $R \& D$ is an active research field, and many studies still need to be performed, pertaining funding is crucial but unfortunately limited. For example, in 2009, Central America countries, on average, spent only $0.22 \%$ of their GDP in Research \& Development. Meanwhile, in the same countries such as Finland, Sweden and Denmark spent 3.93, 3.60 and 3.06\% of their GDP respectively. Among the Central American countries, Costa Rica was the country that invested the most in R\&D projects, around $0.54 \%$ of the GDP [17]. High up-front cost of technologies is one of the greatest hurdles in dissemination of renewable energy technologies, especially in developing countries where lowincome households dominate. Therefore, economic incentives such as microloans and investments subsidies are crucial for successful deployment of such new technologies [17].

Clearly, biomass-based energy systems also require the development of infrastructure capable of handling, processing 
and delivering energy carriers both with respect to the fuel supply and the end product (e.g., electricity, transportation fuel). This goes from the construction of roads to transport any item related to the energy system and, to the creation of mini-grids to supply electricity. For example, transporting animal wastes over long distances will significantly increase the production cost of biogas, making this process less attractive for investors [17]. Related to technical considerations, Sanders presents several inquiries to be addressed in the future development and implementation of a biorefinery [11].

a. How to separate main components or derivatives thereof from biomass at low capital and operational cost, with low energy consumption?

b. How to reduce the logistics cost, e.g. by increasing the (energy) density of biomass or to carry out the biorefinery process close to the origin of the biomass resource?

c. Which of the operations can efficiently be performed at small scale, close to the fields, in order to avoid needles transport?

d. Which new platform chemicals can be derived at sufficient volumes at high yields, low cost and high overall energy efficiencies? How to assess the 'best' and most sustainable approach for producing base chemicals from biomass at the condition that at the same time sufficient food/feed will be available to the world.

e. Which type of biomass can preferably be used for food, for the chemical industry, for transportation fuels and energy, and which preferably for combinations of these? Which fractions of biomass can substitute the highest functionality value and which only the lowest caloric value?

f. How can separation and conversion be combined as to reduce costs and waste streams? Insolubility, electric current, phase separations, extraction, centrifugal forces should be studied in order to derive prospective design rules.

In addition to biomass conversion steps (including pretreatment), separation and purification of biomass converted components into products is of most pivotal importance for biorefinery applications. Compared to conventional chemical processes, the separation in biorefineries may be severely hindered by factors, such as (in case of water-based biorefineries): low feed concentration, product inhibition issues, and/or low product yield leading to very diluted (aqueous) streams that resemble more waste water streams than typical chemical reactor effluents [3].

\section{Conclusion}

Biorefinery comprises a series of promising technologies that include the production of chemicals, energy and materials from biomass. It involves complex integration and optimization biomass separation and conversion processes. Several oily wastes are suitable for biorefinery due to its lipid content and stored energy. It is possible to obtain several small molecules for organic chemistry and biochemistry, biodiesel and other fuel applications.

To achieve the ultimate biorefineries goal, many operations and treatments have been developed. Each one has its own advantages according the biomass used. There is a growing multimillion dollar market revolving around biorefinery applications and it is only expected to grow in the coming years.

\section{References}

1. Zhu L (2015) Biorefinery as a promising approach to promote microalgae industry: An innovative framework. Renewable and Sustainable Energy Reviews 41: 1376-1384.

2. Gavrilescu M (2014) Biorefinery Systems: An Overview. Bioenergy Research: Advances and Applications pp: 219-241.

3. Kiss AA, Lange JP, Schuur B, Brilman DWF, Van der Ham AGJ, et al. (2016) Separation technology-Making a difference in biorefineries. Biomass and Bioenergy, p. 1-14.

4. Ohara H (2003) Biorefinery. Applied Microbiology and Biotechnology 62(5-6): 474-477.

5. Kajaste R (2014) Chemicals from biomass-Managing greenhouse gas emissions in biorefinery production chains - A review. Journal of Cleaner Production 75: 1-10.

6. Octave S, Thomas D (2009) Biorefinery: Toward an industrial metabolism. Biochimie 91(6): 659-664.

7. Silverman JR, John G (2015) Biobased Fat Mimicking Molecular Structuring Agents for Medium-Chain Triglycerides (MCTs) and Other Edible Oils. Journal of Agricultural and Food Chemistry 63(48): 1053610542.

8. Clark JH, Budarin V, Deswarte FEI, Hardy JJE, Kerton FM, et al. (2006) Green chemistry and the biorefinery: A partnership for a sustainable future. Green Chemistry 10: 853-860.

9. Choi S, Song CW, Shin JH, Lee SY (2015) Biorefineries for the production of top building block chemicals and their derivatives. Metabolic Engineering 28: 223-239.

10. Kumar R, Sundari IS, Sen S, Dasgupta N, Chidambaram R (2016) Animal Fat- and Vegetable Oil-Based Platform Chemical Biorefinery. Platform Chemical Biorefinery pp: 361-377.

11. Sanders JPM, Clark JH, Harmsen GJ, Heeres HJ, Heijnen JJ, et al. (2012) Process intensification in the future production of base chemicals from biomass. Process Intensification, Chemical Engineering and Processing 51: 117-136.

12. Saber M, Nakhshiniev B, Yoshikawa K (2016) A review of production and upgrading of algal bio-oil. Renewable and Sustainable Energy Reviews 58: 918-930.

13. Khanna S, Goyal A, Moholkar VS (2012) Microbial conversion of glycerol: present status and future prospects. Critical Reviews in Biotechnology 32(3): 235-262.

14. Mountraki A, Tsakalova M, Panteli A, Papoutsi AI, Kokossis AC (2016) Integrated Waste Management in Multiproduct Biorefineries: Systems Optimization and Analysis of a Real-Life Industrial Plant. Industrial and Engineering Chemistry Research 55(12): 3478-3492.

15. Gerardo ML, Van Den Hende S, Vervaeren H, Coward T, Skill SC (2015) Harvesting of microalgae within a biorefinery approach: A review of the developments and case studies from pilot-plants. Algal Research 11: $248-262$. 
16. Garcia Perez M, Garcia Nunez JA (2013) Nuevos conceptos para biorrefinerías de aceite de palma (New Concepts of Palm Oil Mill Biorefineries). Palmas 34: 66-84.

17. Cutz L, Haro P, Santana D, Johnsson F (2016) Assessment of biomass energy sources and technologies: The case of Central America. Renewable and Sustainable Energy Reviews 58: 1411-1431.

18. Budzianowski WM, Postawa K (2015) Total Chain Integration of sustainable biorefinery systems. Applied Energy 184: 1432-1446.

19. Venkata Mohan S, Nikhil GN, Chiranjeevi P, Nagendranatha Reddy C, Rohit MV, et al. (2016) Waste biorefinery models towards sustainable circular bioeconomy: Critical review and future perspectives Bioresource Technology 215: 2-12.
20. Demirbas A (2010) Biorefinery Technologies for Biomass Upgrading Energy Source. Part A: Recovery, Utilization, and Environmental Effects 32(16): 1547-1558.

21. Coles S (2014) Bioplastics from Lipids. Bio-Based Plastics -Materials and Applications 117-135.

22. Mussgnug JH, Klassen V, Schlüter A, Kruse O (2010) Microalgae as substrates for fermentative biogas production in a combined biorefinery concept. Journal of Biotechnology 150(1): 51-56.

23. Castellucci R, Sachs C, Azcón R, Rolim J, Teramoto S, et al. (2013) Biomass Now-Cultivation and Utilization.

\section{Your next submission with Juniper Publishers will reach you the below assets}

- Quality Editorial service

- Swift Peer Review

- Reprints availability

- E-prints Service

- Manuscript Podcast for convenient understanding

- Global attainment for your research

- Manuscript accessibility in different formats

( Pdf, E-pub, Full Text, Audio)

- Unceasing customer service

Track the below URL for one-step submission https://juniperpublishers.com/online-submission.php 